\title{
Predictive analysis of transmissible quinolone resistance indicates Stenotrophomonas maltophilia as a potential source of a novel family of Qnr determinants
}

\author{
María B Sánchez ${ }^{\dagger 1}$, Alvaro Hernández ${ }^{\dagger 1}$, José M Rodríguez-Martínez², \\ Luis Martínez-Martínez ${ }^{3,4}$ and José L Martínez*1
}

\begin{abstract}
Address: ${ }^{1}$ Departamento de Biotecnología Microbiana, Centro Nacional de Biotecnología, CSIC, Darwin 3, Cantoblanco, 28049-Madrid, and CIBERESP. Spain, ${ }^{2}$ Departamento de Microbiología, Universidad de Sevilla, Av. Sanchez Pizjuan SN 41009-Sevilla, Spain, ${ }^{3}$ Service of Microbiology, University Hospital Marqués de Valdecilla, Santander, Spain and ${ }^{4}$ Department of Molecular Biology, University of Cantabria, Santander, Spain

Email: María B Sánchez - bsanchez@cnb.csic.es; Alvaro Hernández - ahdez@cnb.csic.es; José M Rodríguez-Martínez - jmrodriguez@us.es; Luis Martínez-Martínez - u10315@humv.es; José L Martínez* - jlmtnez@cnb.uam.es

* Corresponding author †Equal contributors
\end{abstract}

Published: 16 September 2008

BMC Microbiology 2008, 8:148 doi:10.1 186/147/-2180-8-148

This article is available from: http://www.biomedcentral.com/I47I-2180/8//48

(C) 2008 Sánchez et al; licensee BioMed Central Ltd.

This is an Open Access article distributed under the terms of the Creative Commons Attribution License (http://creativecommons.org/licenses/by/2.0), which permits unrestricted use, distribution, and reproduction in any medium, provided the original work is properly cited.

\begin{abstract}
Background: Predicting antibiotic resistance before it emerges at clinical settings constitutes a novel approach for preventing and fighting resistance of bacterial pathogens. To analyse the possibility that novel plasmid-encoded quinolone resistance determinants (Qnr) can emerge and disseminate among bacterial pathogens, we searched the presence of those elements in nearly 1000 bacterial genomes and metagenomes.
\end{abstract}

Results: We have found a number of novel potential qnr genes in the chromosomes of aquatic bacteria and in metagenomes from marine organisms. Functional studies of the Stenotrophomonas maltophilia Smqnr gene show that plasmid-encoded SmQnr confers quinolone resistance upon its expression in a heterologous host.

Conclusion: Altogether, the data presented in our work support the notion that predictive studies on antibiotic resistance are feasible, using currently available information on bacterial genomes and with the aid of bioinformatic and functional tools. Our results confirm that aquatic bacteria can be the origin of plasmid-encoded Qnr, and highlight the potential role of S. maltophilia as a source of novel Qnr determinants.

\section{Background}

Quinolones are synthetic antibiotics; therefore, it was thought that the existence of transferable quinolone resistance genes in nature would be unlikely. Resistance mechanisms for these drugs were expected to be only chromosomally encoded. It was believed that only mutations in the quinolone targets (DNA gyrase or topoi- somerase IV) or mutations that led to a permeability decrease and/or overproduction of multidrug resistance (MDR) efflux pumps would result in resistance to these antibiotics $[1,2]$.

It was thus assumed that resistance to quinolones could not spread as the consequence of horizontal gene transfer 
(HGT). Later on, the acquisition of quinolone resistance due to HGT was proposed as a possibility based on in vitro experiments [3]. This was later confirmed in 1998, with the description of a plasmid-encoded quinolone resistance determinant, that was named Qnr, in clinical isolates [4]. More recently two other transferable quinolone resistance determinants have been described, the bifunctional aminoglycoside/quinolones inactivating aminoglycoside acetyltransferase $\mathrm{AAC}\left(6^{\prime}\right)-\mathrm{Ib}-\mathrm{cr}[5,6]$ and the quinolone efflux determinant, QepA $[7,8]$.

Since the discovery of Qnr, the presence of different $q n r$ families (A, B, S) in resistance plasmids [9] has been found worldwide in different bacterial pathogens [10-15]. More recently, plasmid-encoded Qnr determinants have also been described in environmental isolates of Aeromonas spp. [16]. The presence of Qnr genes in chromosomes has also been shown, including QnrA in Shewanella algae, which is likely the origin of plasmid-encoded QnrA determinants [17], and different members of the Qnr family from Vibrionaceae species $[18,19]$.

The Qnr proteins belong to the pentapeptide repeat protein (PRP) family, which is defined by the presence of repetitions in tandem of the pattern $(\mathrm{A} / \mathrm{C} / \mathrm{S} / \mathrm{T} / \mathrm{V})(\mathrm{D} / \mathrm{N})(\mathrm{L} /$ $\mathrm{F})(\mathrm{S} / \mathrm{T} / \mathrm{R})(\mathrm{G} / \mathrm{R})[20-22,17]$. A characteristic feature of the Qnr proteins is that they are formed by two domains of pentapeptide repeats separated by a single glycine. This structure matches a motif of unknown function named Cluster of Orthologous Group of Proteins (COG) 1357 http://www.ncbi.nlm.nih.gov/COG/. Even though members of the PRP family have been identified both in prokaryotes and eukaryotes [22], gnr genes presenting the above described COG1357 motif have a much narrower distribution, mainly in plasmids and in the chromosomes of some bacterial species. The amino acid identity among different Qnr proteins families rates between 39-60\% [23].

Some studies have demonstrated that Qnr protects both gyrase and topoisomerase IV from the activity of quinolones $[15,24-26]$. Other members of the PRP family, that may play a similar role include $\mathrm{McbG}$, which protects microcin B17-producing bacteria from the activity of this DNA replication inhibitor [27] and MfpA [28], a protein that most likely binds GyrA [22] and provides low-level quinolone resistance to Mycobacterium tuberculosis.

Although $q n r$-like elements that contribute to intrinsic quinolone resistance have been described in the chromosome of Enterococcus faecalis [24] and more recently in other Gram-positive bacteria [29], their homology with $q n r$ genes from Gram-negative bacteria is low (around $25 \%$ ), so that this family of resistance elements has not been included in our analysis.
It is important to note that plasmid-encoded quinolone resistance is more prevalent than expected considering the date of the first isolation, which suggests that these plasmids have been circulating for some time before they were first described [30]. This highlights the need to implement methods to predict resistance before it is recognized within clinical settings.

A methodology for predicting the possibility of emergence of a new mechanism of resistance before it appears in bacterial pathogens has been recently proposed [31]. The availability of sequenced genomes allows this type of analysis. This information was used to search for the presence of Qnr determinants in available sequenced bacterial genomes and metagenomes. A putative $q h r$ gene present in the chromosome of the opportunistic pathogen Stenotrophomonas maltophilia was chosen to perform functional analyses. S. maltophilia is a nosocomial pathogen intrinsically resistant to several antimicrobials [32] due to the activity of antibiotic-inactivating enzymes [33-36] and MDR efflux pumps [37-43].

The possibility that chromosomally-encoded S. maltophilia $q n r$ gene (hereafter named as Smqnr) could be functional in a heterologous host has been explored. As the result of our work, we have described new qnr genes in the chromosomes of sequenced bacterial genomes and have found that the Smgnr gene from S. maltophilia renders a low-level quinolone resistance phenotype upon its expression in Escherichia coli. This study demonstrates the feasibility of utilizing currently available databases along with bioinformatics and functional tools as an approach for predicting resistance before it emerges in human pathogens.

\section{Methods \\ Bioinformatic tools and nomenclature of predicted Qnr proteins}

Multiple protein sequence alignments were carried out with the program ClustalW2 http://www.ebi.ac.uk/Tools/ clustalw2/index.html[56]. Similarity search was performed with the program BLAST (NCBI) http:// www.ncbi.nlm.nih.gov/blast/Blast.cgi[57] and genomicBlast http://www.ncbi.nlm.nih.gov/sutils/ genom table.cgi. Identification of conserved motifs [58] ([59] was done by using Conserved Domain Database and Search Service at http://www.ncbi.nlm.nih.gov/Struc ture/cdd/cdd.shtml. The Qnr proteins alignments and homology trees were obtained using CLUSTALW2 and Jalview alignment editor with default parameters [60]. Homology tree was calculated using the method "Average distance using percentage of identity" http:// www.ebi.ac.uk/Tools/clustalw2/index.html.

The predicted Qnr proteins were named following the rules proposed in [61]. 


\section{Bacterial strains and growth conditions}

The bacterial strains and plasmids used are shown in Table 1. The strains were grown in Luria-Bertani (LB) broth [62] at $37^{\circ} \mathrm{C}$ unless otherwise specified.

\section{Susceptibility antibiotic assays}

The susceptibility assays for the different antibiotics were performed in Mueller Hinton broth (Pronadisa) plus Isopropyl-thio- $\beta$-D-galactopyranoside $0.5 \mathrm{mM}$, using the twofold dilution method in 96-well microtiter plates. The results were recorded after $48 \mathrm{~h}$ of incubation at $37^{\circ} \mathrm{C}$. To ensure that the observed changes were consistent, all Minimal Inhibitory Concentrations (MICs) were determined in three independent assays, using different bacterial cultures on different days. In all cases, a control strain containing the plasmid pGEM-T without any insert was included in MICs determinations. In most cases, there were not inter-assay differences in the MIC values. In a few cases, there were one-dilution differences. For the latter, the assay was repeated one more time to further assure assay reliability.

The quinolones used were ciprofloxacin, enoxacin, garenoxacin, grepafloxacin, levofloxacin, moxifloxacin, nalidixic acid, norfloxacin, trovafloxacin and sparfloxacin.

\section{DNA manipulations}

The genomic DNA was extracted using the $\mathrm{GNOME}^{\circledR}$ DNA Kit (Q-BIOgene). The PCR Master Mix (Promega) was used to amplify full-length Sm $q n r$ genes from the different $S$. maltophilia strains without their promoter sequences. The reaction contained $100 \mathrm{ng}$ of genomic DNA of each $S$. maltophilia isolate as template, and $1 \mu \mathrm{M}$ of two different sets of specific Smqnr-primers, QnrM+ (5'-CTTGGCATGGAATCCCTGAT-3')/QnrM-(5'-TGATGCCTACGGCACCAC-3') and QnrMR55+ (5'-CATGGCATGGAATCCCCGA T-3')/QnrMR55-(5'-TGATGTCTACGGCACCAC-3'). We used two sets of primers because the regions around $q n r$ are slightly different in the sequenced $S$. maltophilia strains K279a and R551-3. The reactions had one denaturation step at $94^{\circ} \mathrm{C}$ for 5 minutes, followed by 35 amplification cycles: $94^{\circ} \mathrm{C}$ for 30 seconds, $61^{\circ} \mathrm{C}$ for 45 seconds for annealing, and $72^{\circ} \mathrm{C}$ for 1 minute for elongation, with a final extension step of $72^{\circ} \mathrm{C}$ for 5 minutes. The PCR products (660 bp) obtained from the different $S$. maltophilia strains (Table 1) were electrophoresed in 1\% agarose gels with TAE, purified from the gel with GFX ${ }^{\mathrm{TM}}$ PCR DNA and Gel Band Purification Kit (GE Healthcare) and cloned in pGEM-T plasmid (Promega) generating the corresponding recombinant plasmids (Table 1). The transformation of E. coli KZM120 was made as described [63]. We chose this particular $E$. coli strain because it lacks the major $E$. coli MDR pump and it has been shown previously that the utilization of MDR-defective strains facilitates the characterization of low-level mechanisms of resistance [39]. The transformants were selected in LB agar with $100 \mu \mathrm{g} / \mathrm{ml}$ carbenicillin. The recombinant plasmids were purified using Wizard ${ }^{\circledast}$ Plus SV Miniprep Kit (Promega) and the insert of each plasmid was sequenced using the universal primers M13 forward and M13 reverse by Secugen S.L. http://www.secugen.es/ to confirm the identity of the sequence and establish the orientation of the qnr gene. The sequences of the different Smqnr genes have been deposited at GenBank with numbers from EU681371 to EU681385. Only those plasmids containing the Smqnr gene in the right orientation to allow expression from the pGEM-T lac promoter were used in the functional assays.

Identification of Smqnr in different S. maltophilia isolates The potential presence of Smqnr in both clinical and environmental S. maltophilia strains was evaluated by PCR using the primers qnrI1 (5'-AGAAAGTGGTCGACCAGCAG-3')/qnrI2 (5'-GCAGGTTCGACTTCTTGATG-3') and qnrI3 (5'-CAACGCCAGCTTCATGAACC-3')/qnrI4 (5'AGTTGGCGCTGTTCCAGTCG-3'), which amplify 312 bp and $220 \mathrm{bp}$ fragments of two internal regions in the Smqnr gene of S. maltophilia respectively.

The PCR was made as described above, with the following program, one denaturation cycle at $94^{\circ} \mathrm{C}$ for 5 minutes, followed by 35 amplification cycles: $94^{\circ} \mathrm{C}$ for 30 seconds, $55^{\circ} \mathrm{C}$ for 45 seconds for annealing, and $72^{\circ} \mathrm{C}$ for $30 \mathrm{sec}-$ onds for polymerization, with a final extension of $72^{\circ} \mathrm{C}$ for 5 minutes. The PCR products were analyzed in $1 \%$ agarose gels with TAE.

\section{Expression and identification of the SmQnr protein}

The amount of SmQnr protein was estimated by SDSPAGE [63] and Coomassie blue staining, using cell extracts from bacteria grown in $\mathrm{LB}$ at $37^{\circ} \mathrm{C}$ overnight. The amount of proteins loaded in each lane was normalized to around $4 \times 10^{7}$ cells. In all cases, the global amount of proteins was equal in all lanes of a given gel as can be seen after staining. This serves as a supplementary loading control [64].

To ensure that the protein with the predicted molecular size was indeed SmQnr, the corresponding band was excised and identified, as described [65,39] by Peptide Mass Fingerprinting using MS-MALDI TOF (Proteored: http://www.proteored.org/).

\section{Ethical considerations}

This investigation did not require ethical clearance.

\section{Results and Discussion}

The identification in environmental microorganisms of putative antibiotic resistance elements [44] that might transfer in the near future to pathogenic bacteria is an important topic that we are just beginning to address [31]. 
To that goal a combination of bioinformatic and functional tools can give information to predict resistance before it emerges. Following this concept, we have explored the presence of putative $q n r$ genes in available databases of bacterial genome sequences, because the genetic context of plasmidic $a n r$ genes supports the idea that they have been acquired by HGT. For instance, the plasmid-encoded $q n r A$ gene has been found in a sul1-type integron near an ISCR1 element $[21,45,25]$. A similar structure was found in qnrB2 [46], and qnrS is adjacent to a Tn3 transposon structure $[10,11]$. In contrast, it has been reported that chromosomal qnrA, in Shewanella algae [17] and several $q n r$-like genes identified within the Vibrionacea family [18] are not linked to these mobile genetic elements.

This suggests that chromosomally-encoded $q n r$ genes have not been acquired recently by HGT because of recent antibiotic selective pressure and that yet unidentified chromosomally-encoded $q n r$ genes could be a source of new transferable quinolone resistance genes.

\section{Bioinformatic search of putative qnr genes}

To address the presence of putative qnr genes in the chromosomes of bacteria that could serve as reservoirs of this family of quinolone resistance determinants, a bioinformatic iterative search by sequence homology to several alleles of QnrA, QnrB and QnrS was conducted against genomic or Whole Genome Shotgun Sequence (WGS) databases at the NCBI home page http:// www.ncbi.nlm.nih.gov/. Most of the putative $q n r$ genes found in this search have been previously annotated as hypothetical proteins containing the COG1357 motif. As shown in Figure 1, chromosomally-encoded Qnr proteins present a large degree of homology.

Putative $q n r$ genes were found in 22 out of the 960 genomes tested. The species containing putative $q n r$ genes belong to eight different genera (Figure 2). Most of them inhabit an aquatic environment (in some instances the deep sea) suggesting that plasmidic $q n r$ may have been originated from aquatic bacteria $[17,19,18]$.

Since the large majority of bacterial species have not been cultured so far, metagenomic studies allow a more powerful search of relevant genes in different environments by means of non-culture based methodologies. Thus, besides analysing sequenced genomes, available metagenomic sequence databases http://www.ebi.ac.uk/fasta33/ wgs.html were also searched for the presence of $q$ ar genes. Our study showed that the metagenomes from sea-water [47] contain genes homologous to $q n r$ (hereafter named as Mtgqnr), further supporting the notion that $q n r$ genes are originated from aquatic microorganisms. One of the gnr sequences found in this metagenomic search was highly homologous to plasmid-encoded QnrB [15] proteins (Figure 3 ). It has been shown that $S$. algae is likely the origin of plasmid-encoded $q n r A$ genes [17]. Our analyses, strongly suggest that plasmid-encoded $q n r B$ has also originated from a currently unknown, marine microorganism.

The regions surrounding the chromosomal $q n r$ genes found in our bioinformatics analysis were analysed to ascertain whether, based in the level of sinteny, the origin of these $q n r$ determinants is likely monophyletic or polyphyletic. As shown in Figure 2, and in Additional file 1 , the regions are very similar for some of the analysed species belonging to the same genus, although clear differences are also observed for other species.

For instance, the structure surrounding $q n r$ in Vibrio is very similar for three species, whereas the structure in five other species and in Photobacterium profundum is different. The high level of observed sinteny in these regions, suggests that $q n r$ was acquired by Vibrio parahaemolyticus, Vibrio alginolyticus and Vibrio harveyi before their divergence, and was acquired by the other Vibrionaceae after their divergence. This idea fits well with the relationship of Vibrio Qnr proteins (Figure 4).

Sequence data were inspected for the presence of elements potentially involved in the transfer of $q n r$ genes. As shown in Figure 2, putative transposases or integrases were found in the regions surrounding the $q h r$ determinants in some Shewanella species, and one putative recombinase was found as well in Moritella sp. Whether those elements are remnant of former gene transfer events or constitute a risk for the transference of those qnr genes through HGT to a new host, remains to be established.

In any case, the analyses of available sequences of bacterial genomes suggest that $q n r$ genes are ancient elements in the bacterial chromosomes of a specific subset of bacterial species. Noteworthy, those genes are frequently flanked by genes coding for putative efflux pumps (Figure 2 ), a situation that suggests that Qnr may have functional roles in detoxification processes in water-dwelling bacteria. Although this linkage has not been so far observed for plasmid-encoded $q n r$ genes, the cooperation of two different mechanisms of resistance might be an important element in current resistance to quinolones.

\section{A putative qnr gene is present in the chromosome of $S$. maltophilia}

Once the bioinformatic analysis was made, we focused our efforts in the study of the organism with highest clinical relevance. Among the organisms carrying putative 

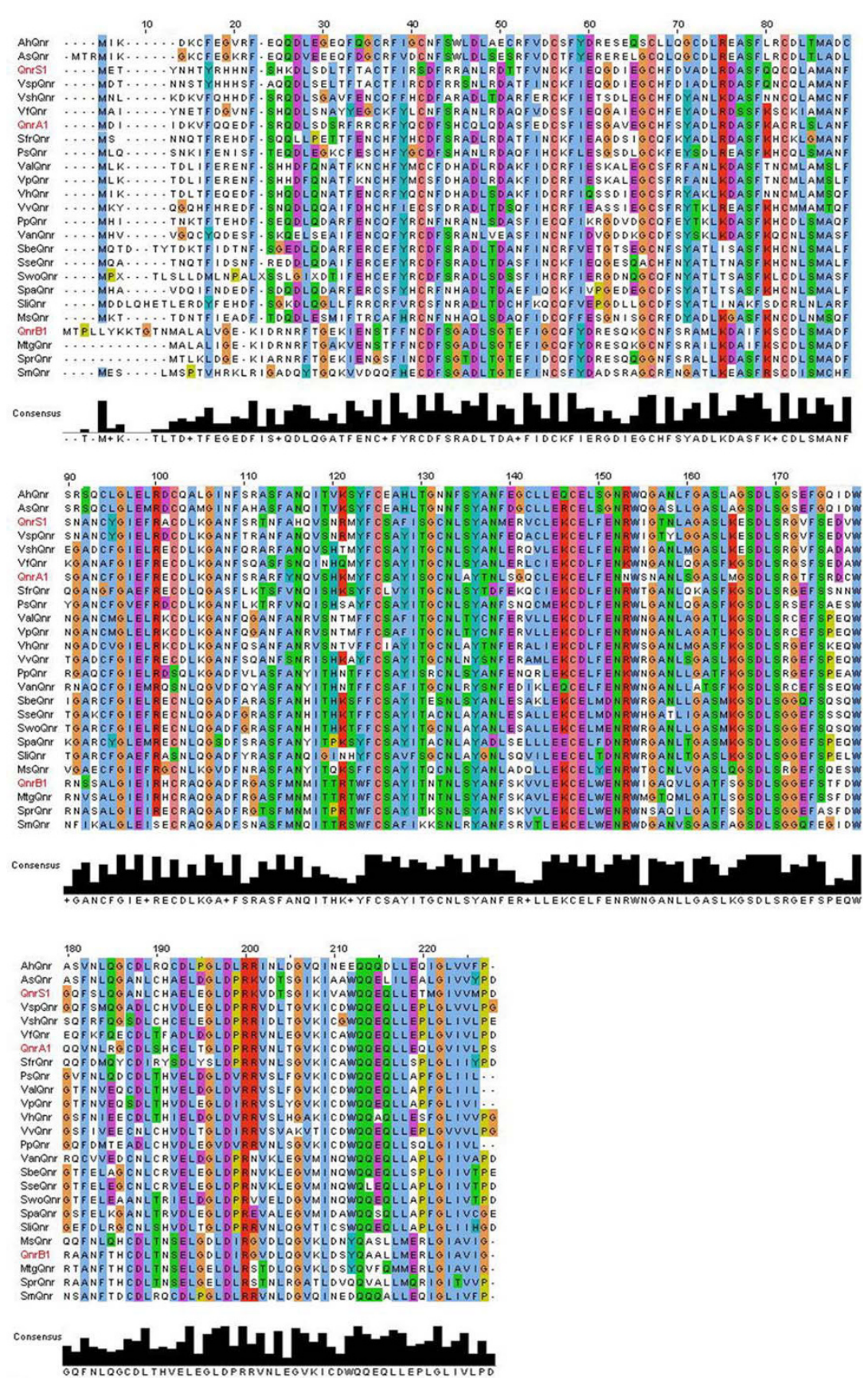

Figure I

Homology of predicted new chromosomally-encoded Qnr proteins. The Figure shows the alignment of chromosomaIly-encoded putative Qnr proteins from the analysis of around 1000 genomes and metagenomes. The figure includes one member of each plasmidic Qnr protein family (highlighted in red), so that the similarities are clearer. The putative Qnr protein from the sea metagenome is also included (MtgQnr). As shown in the Figure, conservation is high along the proteins, although the similarities are lower at their N-terminus. The automated annotation of Swognr presents two stop codons. Since we ignore whether this is a sequence mistake or Swoqnr is a pseudogene, a manual translation of its nucleotide sequence was performed for this alignment. Stop codons are represented with an $X$. Accession numbers of the proteins used for the alignment are: AhQnr (YP_854820.I), AsQnr (YP_00I l43795.I), MsQnr (ZP_0I897I67.I), QnrAI (ACA43024), QnrBI (ABG82I88), QnrSI (ABÜ86826), SbeQnr (ZP_02I57732.I), SfrQnr (YP_750786.I), SliQnr (ABO2234I.I), SmQnr (ZP_01643096.I), SpaQnr (ABV89003.I), SprQnr (YP_00I478290.I), SseQnr (ABV3525I.I), SwoQnr (ZP_0I539I89.I), PpQnr (CAG2I998.I), PsQnr (EAS39797.I), ValQnr (ZP_0I26I394.I), VanQnr (ZP_0I234687.I), VfQnr (ZP_02I36549.I), VhQnr (ZP_0I985396.I), VpQnr (ZP_01990287.I), VshQnr (ZP_01866232.I), VspQnr (ZP_00989608.I), VvQnr (AAO07889.I) and MtgQnr (AACY020347520). 


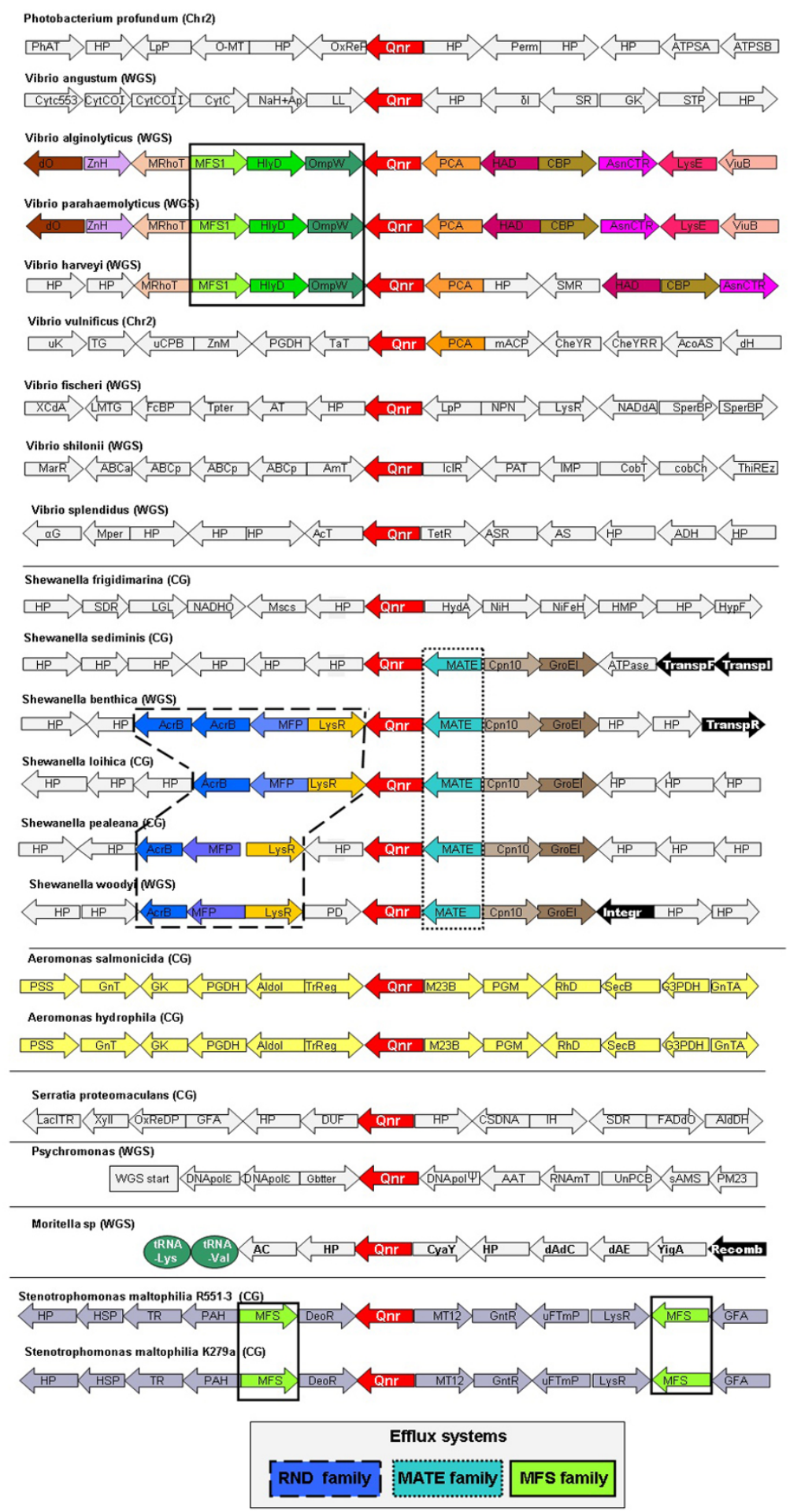

Figure 2

Predicted qnr genes in genome databases. The structure of the regions surrounding predicted qnr genes (in red) is shown. Elements that might contribute to transfer of those genes are highlighted in black. The presence of putative MDR systems is also highlighted. WGS (whole genome shotgun), CG (Complete genome), Chr (Chromosome). Only those putative qnr determinants showing more than $45 \%$ identity with known plasmid-encoded QnrA or QnrB determinants were included in the analysis. The abbreviations used in the Figure are shown in Additional file I. 


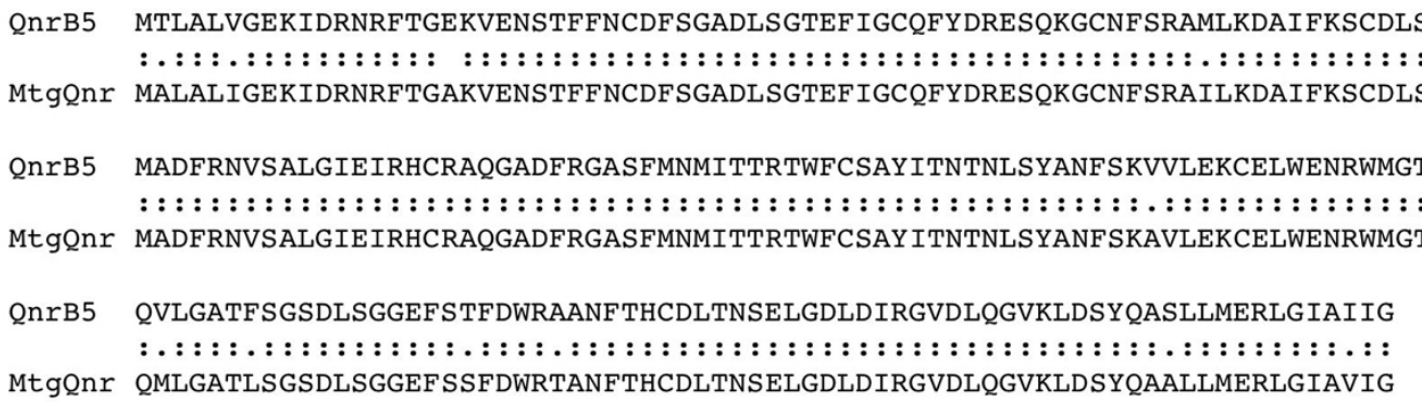

\section{Figure 3}

Alignment of the plasmid-encoded protein QnrB with a putative Qnr protein encoded in a marine metagenome. The percentage of identity between both proteins was $94.9 \%$, with a homology of 99.5\%. Top QnrB5, bottom Qnr protein from a marine metagenome (MtgQnr). Two dots indicate identical amino acids, one dot homologous amino acids.

uncharacterized $q n r$ genes we chose S. maltophilia, which is an intrinsically resistant opportunistic pathogen responsible for $4.3 \%$ of Gram-negative infections among intensive care units patients in the USA [48].

Noteworthy, in S. maltophilia resistance to fluoroquinolones (particularly to less active ones, such as norfloxacin) is not always accompanied by high level resistance to nalidixic acid, which is the usual and classical association in Enterobacteria. Interestingly, resistance to fluoroquinolones and susceptibility to nalidixic acid in S. maltophilia resemble the phenotype recently observed by Cano ME et al (unpublished results) in some Enterobacteriaceae containing $q n r$ genes. A putative $q n r$ gene (Smqnr) was identified in the two available full-genome sequences of $S$. maltophilia: the clinical isolate K279a http:// www.sanger.ac.uk/Projects/S_maltophilia/[49], and the environmental strain R551-3, http://genome.jgi-psf.org/ draft microbes/stema/stema.home.html. As shown in Figure 2, the genomic structure around Smgnr was the same in both strains, in spite their different (clinical and environmental) source of isolation.

This high degree of sinteny, together with the lack of elements involved in HGT near Smqnr suggests that this gene has an ancient origin in S. maltophilia. Further confirmation of this likely monophyletic origin has been obtained from the analyses of the Smqnr sequence from different $S$. maltophilia isolates in this study. The predicted translation of Smqnr sequence is a 219 amino acid protein (Figure 5), containing tandem repetitions of the pattern $(\mathrm{A} / \mathrm{C} / \mathrm{S} / \mathrm{T} /$ $\mathrm{V})(\mathrm{D} / \mathrm{N})(\mathrm{L} / \mathrm{F})(\mathrm{S} / \mathrm{T} / \mathrm{R})(\mathrm{G} / \mathrm{R})$ typical of the pentapeptide family $[20,18,22]$, with two domains of pentapeptide repeats separated by a single glycine, that corresponds to a COG1357 motif.

\section{Prevalence of the Smqnr gene in Stenotrophomonas maltophilia strains}

Since Smqnr might be involved in quinolone resistance, we wanted to ascertain the prevalence of this gene in $S$. maltophilia populations. To that goal, and since the sequences of the qnr genes of the strains K279a and R5513 were slightly different, two pairs of oligonucleotides QnrM+/- and QnrMR55+/- were designed to amplify Smanr genes from different $S$. maltophilia strains. The set of analysed strains comprised both clinical and environmental S. maltophilia isolates (Table 1).

The SmQnr sequences from the different strains display a high amino acid identity, ranking from 94 to 100\% (Figure 5). However the amino acid identity of the SmQnr protein encoded in the chromosome of the sequenced $S$. maltophilia strain K279a, is low compared with other known Qnr proteins, sharing 38\%, 59\%, 38\% and 41\% with QnrA1 (AY070235), QnrB2 (DQ351241), QnrS2 (AB187515) and VvQnr (DQ889870) respectively. For this reason we consider that Smqnr represents a possible new subtype of $q n r$ genes. Clustal analysis (Figure 4) indicates that the SmQnr protein clusters with plasmidic QnrB proteins, although forms a separate branch. Therefore, our results suggest that SmQnr is the first characterized chromosomally encoded QnrB-like protein.

We were unable to amplify the full $q n r$ gene from the isolates E729, F227, E301, F861 and e-p5. Since qnr sequences where slightly different in K279a and R551-3, as well as in the isolates analysed in the present study, two new pairs of oligonucleotides (qnrI1/qnrI2 and qnrI3/ qnrI4) were used to amplify an internal conserved region of Smqnr. Positive amplification was obtained in all cases (not shown) indicating that all S. maltophilia isolates contained the qnr gene. 


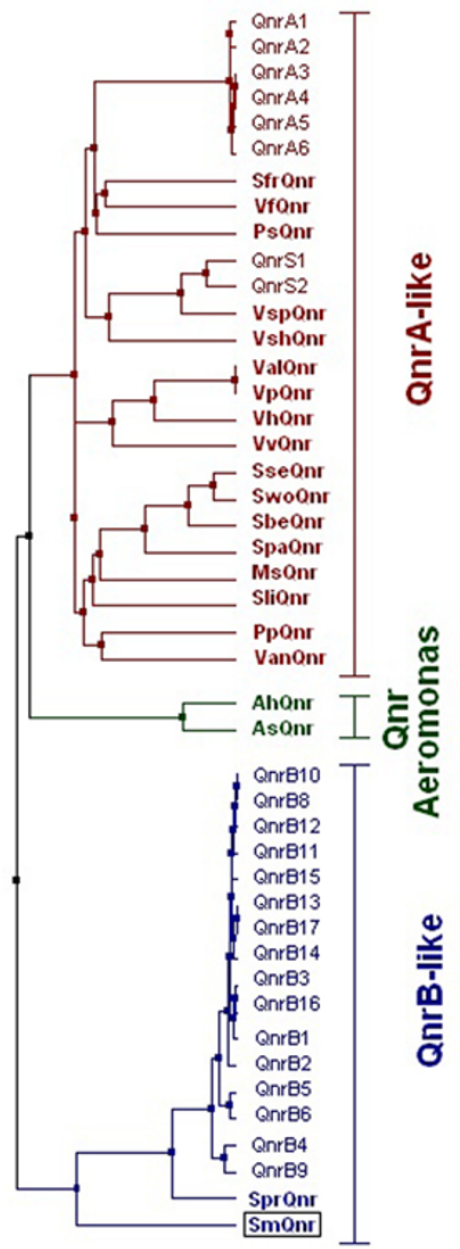

\section{Figure 4}

Clustal analysis of Qnr proteins. Characterized and predicted Qnr proteins were clustered. The tree was calculated using the average percentage of identity. Other two members of the pentapeptide repeat family with proven resistance to fluoroquinolones, MfpA from Mycobacterium tuberculosis and McbG from Escherichia coli, were included in the analysis, but are not shown because they plotted out of the Qnr tree. Chromosomally-encoded Qnr proteins are highlighted in bold. The position of the SmQnr protein from S. maltophilia as a member of the QnrB cluster is highlighted with a square. Novel Qnr proteins are named according to the species where they are originated: AhQnr (Aeromonas hydrophila), AsQnr (Aeromonas salmonicida), MsQnr (Moritella sp), SprQnr (Serratia proteamaculans), SbeQnr (Shewanella benthica), SfrQnr (Shewanella frigidimarina), SliQnr (Shewanella loihica), SpaQnr (Shewanella pealeana), SseQnr (Shewanella sediminis), SwoQnr (Shewanella woodyi), SmQnr (Stenotrophomonas maltophilia), PsQnr (Psychromonas), ValQnr (Vibrio alginolyticus), VanQnr (Vibrio angustum), VfQnr (Vibrio fischeri), VhQnr (Vibrio harveyi), VshQnr (Vibrio shilonii), VspQnr (Vibrio splendidus), VvQnr (Vibrio vulnificus).

\section{Functional analysis of SmQnr as a quinolone resistance determinant in a heterologous host}

To ascertain whether SmQnr might contribute to quinolone resistance in a heterologous host, the different alleles of the $q n r$ gene obtained from different $S$. maltophilia strains were cloned into the plasmid pGEM-T. Corresponding recombinant plasmids, containing the Smqnr gene, were expressed in E. coli, and the quinolone susceptibility of strains expressing SmQnr was compared to that of the isogenic E. coli strain. We found that in trans expression of SmQnr from different recombinant plasmid results in a 2 to 32 -fols decrease in the quinolone susceptibility of E. coli (Table 2).

Noteworthy, different recombinant strains presented slight, but consistent, differences in their susceptibility to several quinolones (Table 2). It has been previously stated that transconjugants of plasmids containing the $q n r$ gene present disparate levels of quinolone resistance, likely due to different levels of expression of the Qnr protein in the 


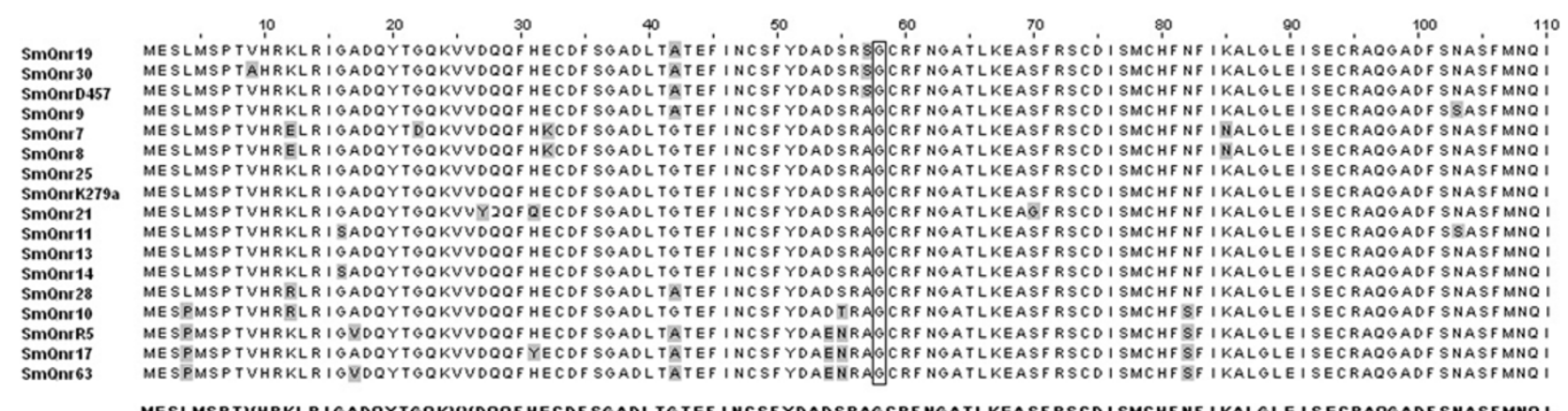

MESLMSPTVHRKLR I GADQYTGQKVVDQQF HECDF SGADLTGTEF INCSFYDADSRAGCRF NGATLKEASF RSCD I SMCHF NF I KALGLE ISECRAQGADF SNASFMNO I

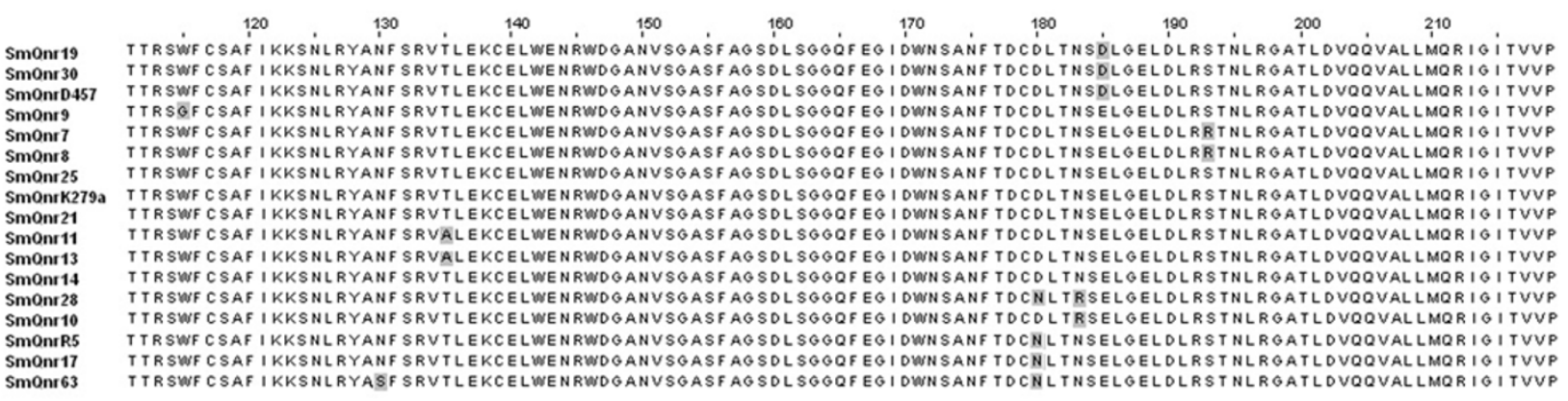

TTRSWFCSAF I KKSNLRYANF SRVILEKCEL WENRWDGANVSGASFAGSDLSGGQFEGI DWNSANF TDCDLTNSELGELDLRSTNLRGATLDVQOVALLMOR IGITUVP

\section{Figure 5}

Alignment of deduced amino acid sequences of different SmQnr proteins. The amino acids that changed in the different SmQnr alleles are highlighted in a grey square. The glycine residue $(G)$ separating the two domains of pentapetide repeats, is marked with a box.

different transconjugants [50]. To ascertain whether this could be the situation with the different SmQnr-expressing plasmids, the expression of the SmQnr protein was estimated in the different $E$. coli transformants. As shown in Figure 6A, transformants containing either pBS3.25 or pBS3.13 expressed higher levels of SmQnr than the other transformants.

During our work, we detected that some Qnr-expressing plasmids were lost after subculturing even in the presence of ampicillin, although they could be maintained in the presence of carbenicillin. Plasmid loss after the bacteria has degraded the selective antibiotic is an indication of physiological burden [51]. Our results suggest that highlevel expression of SmQnr is likely harmful for E. coli. It is possible that, as described for other systems [52], a fast adaptation between the host cell and the plasmid occurred that results in reduced levels of SmQnr and that this allowed some of the clones to overcome the putative SmQnr toxicity. To address this possibility, E. coli KZM120 was retransformed with the plasmids pBS3.8, pBS3.25 and pBS3.13. Two different clones from each retransformation were chosen and their susceptibility to quinolones tested. As shown in Table 3, an overall reduc- tion in MICs as well as in the level of SmQnr expression (Figure 6B) was observed for the new transformants containing the plasmids pBS3.8, pBS3.25 and pBS3.13. However, the phenotype of reduced susceptibility to quinolones was maintained. Increased resistance due to higher expression of antibiotic resistance genes has been described mainly associated with plasmidic beta-lactamases [53-55]. Our results together with already published data indicate that gene-dosage might be relevant for $q n r$ mediated quinolone resistance.

\section{Conclusion}

By using a combination of bioinformatics and functional tools, we found a number of novel putative $q n r$ genes in the chromosomes of aquatic bacteria and in metagenomes from marine organisms. This further supports the notion that the origins of $q n r$ determinants are in waterdwelling bacteria. It has been recently shown that Aeromonas spp. obtained from water samples contain plasmidencoded $q n r$ genes [16]. These results have been interpreted as a consequence of the presence of quinolones in rivers that drive the evolution of aquatic bacteria towards quinolone resistance. This explanation is likely true for plasmid-encoded $q n r$ genes. However, the presence of $q n r$ - 
Table I: Strains and plasmids used in this work.

\begin{tabular}{|c|c|c|}
\hline Strain or plasmid & Description & Reference or source \\
\hline \multicolumn{3}{|l|}{ Escherichia coli } \\
\hline KZMI 20 & $\triangle a c r A B:: \operatorname{Tn} 903 \mathrm{Kan}^{r}$ & {$[66]$} \\
\hline \multicolumn{3}{|l|}{ S. maltophilia } \\
\hline C357 & Urinary isolate & {$[67]$} \\
\hline $\mathrm{CO} 47$ & Clinical & Lab collection \\
\hline $\mathrm{CO} 48$ & Bronchial aspirate isolate & {$[67]$} \\
\hline D388 & Urinary isolate & {$[67]$} \\
\hline D457 & Bronchial aspirate isolate & [38] \\
\hline E30I & Urinary isolate & [67] \\
\hline E539 & Infected wound isolate & {$[67]$} \\
\hline E729 & Urinary isolate & [67] \\
\hline E759 & Sputum isolate & [67] \\
\hline E824 & Blood & [67] \\
\hline E847 & Clinical & [39] \\
\hline E923 & Sputum isolate & {$[67]$} \\
\hline E999 & Respiratory secretion isolate & [67] \\
\hline F227 & Blood culture isolate & [67] \\
\hline F375 & Blood culture isolate & {$[67]$} \\
\hline F86I & Sputum isolate & [67] \\
\hline G5I & Blood culture isolate & [67] \\
\hline e-a2l & Sewage (Braunschweig, Germany) & {$[68]$} \\
\hline e-a63 & Sewage (Braunschweig, Germany) & Provided by Gabrielle Berg \\
\hline e-p5 & Rhizosphere of Brassica napus L. (Rostock, Germany) & {$[68]$} \\
\hline R55I-3 & Environmental & Provided by Daniel van der Lelie \\
\hline \multicolumn{3}{|l|}{ Plasmids } \\
\hline PGEM-T & Cloning vector with polyA, amp ${ }^{r}$ & Promega \\
\hline pBS3.7 & pGEM-T with Smqnr of S. maltophilia E759 & This work \\
\hline pBS3.8 & PGEM-T with Smqnr of S. maltophilia E923 & This work \\
\hline pBS3.9 & PGEM-T with Smqnr of S. maltophilia E999 & This work \\
\hline pBS3.10 & PGEM-T with Smqnr of S. maltophilia G5I & This work \\
\hline pBS3.II & PGEM-T with Smqnr of S. maltophilia E539 & This work \\
\hline pBS3.13 & PGEM-T with Smqnr of S. maltophilia D388 & This work \\
\hline pBS3.14 & pGEM-T with Smqnr of S. maltophilia CO48 & This work \\
\hline pBS3.17 & PGEM-T with Smqnr of S. maltophilia C357 & This work \\
\hline pBS3.19 & PGEM-T with Smqnr of S. maltophilia F375 & This work \\
\hline pBS3.25 & PGEM-T with Smqnr of S. maltophilia E847 & This work \\
\hline pBS3.28 & PGEM-T with Smqnr of S. maltophilia CO47 & This work \\
\hline pBS3.30 & pGEM-T with Smqnr of S. maltophilia E824 & This work \\
\hline pBS3.D457 & pGEM-T with Smqnr of S. maltophilia D457 & This work \\
\hline pBS3.R5 & PGEM-T with Smqnr of S. maltophilia R55I-3 & This work \\
\hline pBS3.21 & PGEM-T with Smqnr of S. maltophilia e-a2 I & This work \\
\hline pBS3.63 & pGEM-T with Smqnr of S. maltophilia e-a63 & This work \\
\hline
\end{tabular}

like determinants with conserved genetic environments in the chromosomes of water-borne bacteria, together with the fact that at least for $S$. maltophilia the $q n r$ gene is present in all strains, suggests that their presence in bacterial chromosomes is not the consequence of recent HGT events due to the selective pressure of quinolones. Thus, we would expect an ecological role in aquatic environments for those qnr-like determinants in addition to quinolone resistance.
The study of the S. maltophilia Smgnr gene indicates that SmQnr confers quinolone resistance when expressed from a plasmid in a heterologous host, highlighting the risk of those elements for future development of novel plasmid-mediated Qnr resistance. Altogether, our data supports the reliability of using a predictive approach for analysing antibiotic resistance elements that may potentially disseminate among bacterial populations. 
Table 2: MICs $(\mu \mathrm{g} / \mathrm{ml})$ of quinolones for E. coli KZMI 20 carrying different Smqnr genes from S. maltophilia isolates.

\begin{tabular}{|c|c|c|c|c|c|c|c|c|c|c|}
\hline \multirow[t]{2}{*}{ Plasmids } & \multicolumn{10}{|c|}{ Antibiotics } \\
\hline & NAL & NOR & SPA & CIP & ENX & LEV & GAR & GRP & TRV & MOX \\
\hline pGEM-T & 1 & 0.016 & 0.032 & 0.002 & 0.032 & 0.004 & 0.002 & 0.001 & 0.004 & 0.004 \\
\hline pBS3.7 & 1 & 0.016 & 0.032 & 0.004 & 0.064 & 0.008 & 0.016 & 0.004 & 0.016 & 0.008 \\
\hline pBS3.8 & 1 & 0.032 & 0.032 & 0.008 & 0.064 & 0.016 & 0.032 & 0.008 & 0.032 & 0.016 \\
\hline pBS3.9 & 1 & 0.016 & 0.032 & 0.004 & 0.064 & 0.008 & 0.016 & 0.016 & 0.032 & 0.016 \\
\hline pBS3.10 & I & 0.016 & 0.032 & 0.004 & 0.064 & 0.008 & 0.008 & 0.004 & 0.016 & 0.016 \\
\hline pBS3.II & 1 & 0.016 & 0.032 & 0.004 & 0.064 & 0.008 & 0.004 & 0.004 & 0.008 & 0.008 \\
\hline pBS3.13 & 1 & 0.016 & 0.032 & 0.004 & 0.064 & 0.008 & 0.008 & 0.004 & 0.016 & 0.016 \\
\hline pBS3.14 & 1 & 0.016 & 0.032 & 0.004 & 0.064 & 0.008 & 0.008 & 0.004 & 0.016 & 0.016 \\
\hline pBS3.17 & 1 & 0.016 & 0.032 & 0.004 & 0.064 & 0.008 & 0.016 & 0.008 & 0.016 & 0.016 \\
\hline pBS3.19 & 1 & 0.016 & 0.032 & 0.004 & 0.064 & 0.008 & 0.008 & 0.004 & 0.016 & 0.008 \\
\hline pBS3.25 & 1 & 0.016 & 0.032 & 0.004 & 0.064 & 0.008 & 0.064 & 0.016 & 0.032 & 0.032 \\
\hline pBS3.28 & 1 & 0.016 & 0.032 & 0.004 & 0.064 & 0.008 & 0.004 & 0.002 & 0.008 & 0.008 \\
\hline pBS3.30 & 1 & 0.016 & 0.032 & 0.004 & 0.064 & 0.008 & 0.004 & 0.002 & 0.008 & 0.008 \\
\hline pBS3.R5 & 1 & 0.016 & 0.032 & 0.004 & 0.064 & 0.008 & 0.008 & 0.002 & 0.016 & 0.008 \\
\hline pBS3.2I & 1 & 0.016 & 0.032 & 0.004 & 0.064 & 0.008 & 0.016 & 0.004 & 0.016 & 0.016 \\
\hline pBS3.63 & I & 0.016 & 0.032 & 0.004 & 0.032 & 0.008 & 0.008 & 0.002 & 0.008 & 0.008 \\
\hline
\end{tabular}

NAL; nalidixic acid, NOR; norfloxacin, SPA; sparfloxacin, CIP; ciprofloxacin, ENX; enoxacin, LEV; levofloxacin, GAR; garenoxacin, GRP; grepafloxacin, TRV; trovafloxacin, MOX; moxifloxacin.
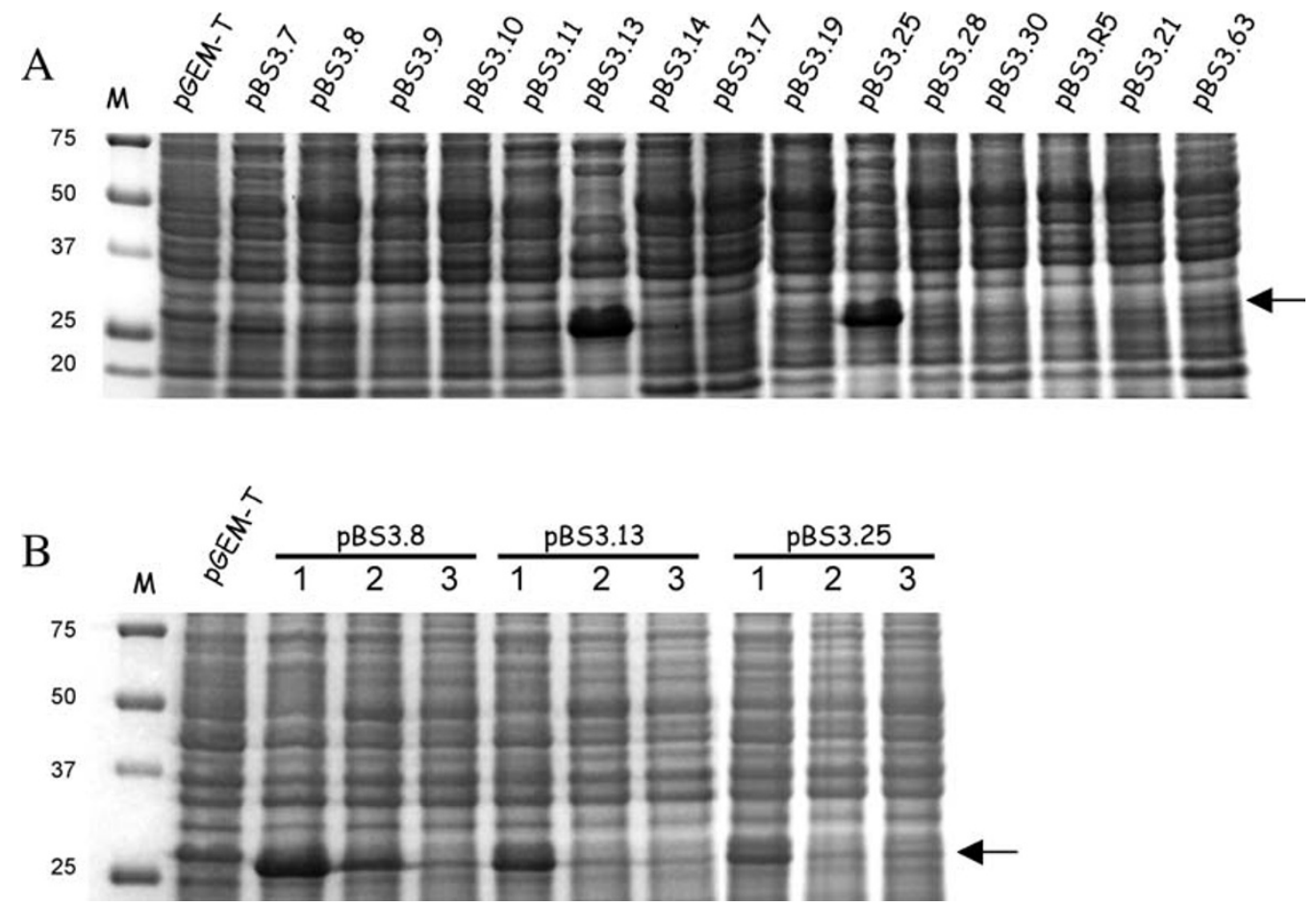

Figure 6

Estimation of the expression of different SmQnr alleles in E. coli. M, molecular mass standards, lane 2, E. coli KZMI20 $(\triangle a c r A B)$ carrying PGEM-T (negative control), (A) Expression of SmQnr by E. coli strains containing different plasmids that encode different SmQnr alleles. The SmQnr protein used for its identification by MS-MALDI-TOF (see Methods) was the allele encoded by pBS3.I3. (B) To establish the effect of the level of expression of SmQnr on the susceptibility to antibiotics, the original clone $(\mathrm{I})$ and two re-transformants ( 2 and 3$)$ were analysed for each of the plasmids pBS3.8, pBS3.I3 and pBS3.25. The position of SmQnr is indicated with an arrow. 
Table 3: MICs $(\mu \mathrm{g} / \mathrm{ml})$ of quinolones for different colonies of $E$ coli KZMI 20 containing each of the plasmids pBS3.8, pBS3.25 and PBS3.13

\begin{tabular}{|c|c|c|c|c|c|c|c|c|c|c|}
\hline \multirow[t]{2}{*}{ Plasmids } & \multicolumn{10}{|c|}{ Antibiotics } \\
\hline & NAL & NOR & SPA & CIP & ENX & LEV & GAR & GRP & TRV & MOX \\
\hline PGEM-T & I & 0.016 & 0.032 & 0.002 & 0.032 & 0.004 & 0.002 & 0.001 & 0.004 & 0.004 \\
\hline pBS3.8 I & 1 & 0.032 & 0.032 & 0.008 & 0.064 & 0.016 & 0.032 & 0.008 & 0.032 & 0.016 \\
\hline pBS3.8 2 & 1 & 0.016 & 0.032 & 0.004 & 0.064 & 0.008 & 0.016 & 0.008 & 0.032 & 0.016 \\
\hline PBS3.8 3 & I & 0.016 & 0.032 & 0.004 & 0.064 & 0.008 & 0.016 & 0.008 & 0.032 & 0.016 \\
\hline pBS3.13 I & 1 & 0.016 & 0.032 & 0.004 & 0.064 & 0.008 & 0.008 & 0.004 & 0.016 & 0.016 \\
\hline pBS3.132 & 1 & 0.016 & 0.032 & 0.004 & 0.064 & 0.008 & 0.002 & 0.002 & 0.008 & 0.008 \\
\hline pBS3.133 & I & 0.016 & 0.032 & 0.004 & 0.064 & 0.008 & 0.002 & 0.002 & 0.008 & 0.008 \\
\hline pBS3.25 I & 1 & 0.016 & 0.032 & 0.004 & 0.064 & 0.008 & 0.064 & 0.016 & 0.032 & 0.032 \\
\hline pBS3.25 2 & I & 0.016 & 0.032 & 0.004 & 0.064 & 0.008 & 0.008 & 0.004 & 0.016 & 0.008 \\
\hline pBS3.25 3 & I & 0.016 & 0.032 & 0.004 & 0.064 & 0.008 & 0.008 & 0.004 & 0.016 & 0.008 \\
\hline
\end{tabular}

Three colonies were tested for each plasmid.

NAL; nalidixic acid, NOR; norfloxacin, SPA; sparfloxacin, CIP; ciprofloxacin, ENX; enoxacin, LEV; levofloxacin, GAR; garenoxacin, GRP; grepafloxacin, TRV; trovafloxacin, MOX; moxifloxacin.

\section{Authors' contributions}

All the authors contributed to write the article. JLM and LMM designed the work. AH and MBS contributed equally to the experimental and bioinformatic work. All authors read and approved the final version of the manuscript.

\section{Additional material}

\section{Additional file 1}

Microsoft excel document containing the descriptions of the genes shown in Figure 2.

Click here for file

[http://www.biomedcentral.com/content/supplementary/14712180-8-148-S1.xls]

\section{Acknowledgements}

This work has been supported by grants BIO2005-04278, LSHM-CT-2005518152 and LSHM-CT-2005-018705. L. M-M and J.M. R.-M. are supported by REIPI, RD06/0008 from ISCIII, Ministerio de Sanidad y Consumo, Spain. Thanks are given to Gabrielle Berg for the supply of environmental S. maltophilia strains and to Carolina Alvarez-Ortega for English proofreading.

\section{References}

I. Hooper DC: Mechanisms of fluoroquinolone resistance. Drug Resist Updat 1999, 2:38-55.

2. Martinez JL, Alonso A, Gomez-Gomez JM, Baquero F: Quinolone resistance by mutations in chromosomal gyrase genes. Just the tip of the iceberg? J Antimicrob Chemother 1998, 42:683-688.

3. Gomez-Gomez JM, Blazquez J, Espinosa LE De Los Monteros, Baquero MR, Baquero $F$, Martinez JL: In vitro plasmid-encoded resistance to quinolones. FEMS Microbiol Lett 1997, I 54:27I-276.

4. Martinez-Martinez L, Pascual A, Jacoby GA: Quinolone resistance from a transferable plasmid. Lancet 1998, 351:797-799.

5. Robicsek A, Strahilevitz J, Jacoby GA, Macielag M, Abbanat D, Park $\mathrm{CH}$, Bush K, Hooper DC: Fluoroquinolone-modifying enzyme: a new adaptation of a common aminoglycoside acetyltransferase. Nat Med 2006, 12:83-88.
6. Park CH, Robicsek A, Jacoby GA, Sahm D, Hooper DC: Prevalence in the United States of aac(6')-lb-cr encoding a ciprofloxacinmodifying enzyme. Antimicrob Agents Chemother 2006, 50:3953-3955.

7. Yamane K, Wachino J, Suzuki S, Kimura K, Shibata N, Kato H, Shibayama K, Konda T, Arakawa Y: New plasmid-mediated fluoroquinolone efflux pump, QepA, found in an Escherichia coli clinical isolate. Antimicrob Agents Chemother 2007, 5 I :3354-3360.

8. Perichon B, Courvalin P, Galimand M: Transferable resistance to aminoglycosides by methylation of GI405 in I6S rRNA and to hydrophilic fluoroquinolones by QepA-mediated efflux in Escherichia coli. Antimicrob Agents Chemother 2007, 5 I:2464-2469.

9. Courvalin P: Plasmid-mediated 4-quinolone resistance: a real or apparent absence? Antimicrob Agents Chemother 1990, 34:681-684.

10. Hata M, Suzuki M, Matsumoto M, Takahashi M, Sato K, Ibe S, Sakae K: Cloning of a novel gene for quinolone resistance from a transferable plasmid in Shigella flexneri 2b. Antimicrob Agents Chemother 2005, 49:801-803.

II. Poirel L, Nguyen TV, Weintraub A, Leviandier C, Nordmann P: Plasmid-mediated quinolone resistance determinant qnrS in Enterobacter cloacae. Clin Microbiol Infect 2006, 12:1021-1023.

12. Wu JJ, Ko WC, Tsai SH, Yan JJ: Prevalence of plasmid-mediated quinolone resistance determinants QnrA, QnrB, and QnrS among clinical isolates of Enterobacter cloacae in a Taiwanese hospital. Antimicrob Agents Chemother 2007, 5 I: I 223-1227.

13. Poirel L, Villa L, Bertini A, Pitout JD, Nordmann P, Carattoli A: Expanded-spectrum beta-lactamase and plasmid-mediated quinolone resistance. Emerg Infect Dis 2007, 13:803-805.

14. Strahilevitz J, Engelstein D, Adler A, Temper V, Moses AE, Block C, Robicsek $A$ : Changes in qnr prevalence and fluoroquinolone resistance in clinical isolates of Klebsiella pneumoniae and Enterobacter spp. collected from 1990 to 2005. Antimicrob Agents Chemother 2007, 5 I:300I-3003.

15. Jacoby GA, Walsh KE, Mills DM, Walker VJ, Oh H, Robicsek A, Hooper DC: qnrB, another plasmid-mediated gene for quinolone resistance. Antimicrob Agents Chemother 2006, 50:1178-1182

16. Cattoir V, Poirel L, Aubert C, Soussy CJ, Nordmann P: Unexpected Occurrence of Plasmid-Mediated Quinolone Resistance Determinants in Environmental Aeromonas spp. Emerg Infect Dis 2008, 14:23।-237.

17. Poirel L, Rodriguez-Martinez JM, Mammeri H, Liard A, Nordmann P: Origin of plasmid-mediated quinolone resistance determinant QnrA. Antimicrob Agents Chemother 2005, 49:3523-3525.

18. Poirel L, Liard A, Rodriguez-Martinez JM, Nordmann P: Vibrionaceae as a possible source of $\mathrm{Qnr}$-like quinolone resistance determinants. J Antimicrob Chemother 2005, 56: I I I8-I I2I. 
19. Cattoir V, Poirel L, Mazel D, Soussy CJ, Nordmann P: Vibrio splendidus as the source of plasmid-mediated QnrS-like quinolone resistance determinants. Antimicrob Agents Chemother 2007, 5 I:2650-265 I

20. Bateman A, Murzin AG, Teichmann SA: Structure and distribution of pentapeptide repeats in bacteria. Protein Sci 1998, 7:|477-|480.

21. Mammeri H, Loo M Van De, Poirel L, Martinez-Martinez L, Nordmann P: Emergence of plasmid-mediated quinolone resistance in Escherichia coli in Europe. Antimicrob Agents Chemother 2005, 49:7I-76.

22. Vetting MW, Hegde SS, Fajardo JE, Fiser A, Roderick SL, Takiff HE, Blanchard JS: Pentapeptide repeat proteins. Biochemistry 2006, 45: $1-10$.

23. Nordmann P, Poirel L: Emergence of plasmid-mediated resistance to quinolones in Enterobacteriaceae. J Antimicrob Chemother 2005, 56:463-469.

24. Arsene S, Leclercq R: Role of a qnr-like gene in the intrinsic resistance of Enterococcus faecalis to fluoroquinolones. Antimicrob Agents Chemother 2007, 5 I:3254-3258.

25. Tran JH, Jacoby GA: Mechanism of plasmid-mediated quinolone resistance. Proc Natl Acad Sci USA 2002, 99:5638-5642.

26. Tran $\mathrm{H}$, Jacoby GA, Hooper DC: Interaction of the plasmidencoded quinolone resistance protein Qnr with Escherichia coli DNA gyrase. Antimicrob Agents Chemother 2005, 49: I I8-I 25.

27. Garrido MC, Herrero M, Kolter R, Moreno F: The export of the DNA replication inhibitor Microcin $B I 7$ provides immunity for the host cell. Embo J 1988, 7:1853-1862.

28. Montero C, Mateu G, Rodriguez $\mathrm{R}$, Takiff $\mathrm{H}$ : Intrinsic resistance of Mycobacterium smegmatis to fluoroquinolones may be influenced by new pentapeptide protein MfpA. Antimicrob Agents Chemother 2001, 45:3387-3392.

29. Rodriguez-Martinez JM, Velasco C, Briales A, Garcia I, Conejo MC, Pascual A: Qnr-like pentapeptide repeat proteins in Grampositive bacteria. J Antimicrob Chemother 2008, 6 I: | 240- I 243.

30. Robicsek A, Jacoby GA, Hooper DC: The worldwide emergence of plasmid-mediated quinolone resistance. Lancet Infect Dis 2006, 6:629-640.

31. Martinez JL, Baquero F, Andersson DI: Predicting antibiotic resistance. Nat Rev Microbiol 2007, 5:958-965.

32. Denton M, Kerr KG: Microbiological and clinical aspects of infection associated with Stenotrophomonas maltophilia. Clin Microbiol Rev 1998, I I:57-80.

33. Avison MB, Higgins CS, von Heldreich CJ, Bennett PM, Walsh TR: Plasmid location and molecular heterogeneity of the LI and L2 beta-lactamase genes of Stenotrophomonas maltophilia. Antimicrob Agents Chemother 2001, 45:413-419.

34. Gould VC, Okazaki A, Avison MB: Beta-lactam resistance and beta-lactamase expression in clinical Stenotrophomonas maltophilia isolates having defined phylogenetic relationships. I Antimicrob Chemother 2006, 57:199-203.

35. Li XZ, Zhang L, McKay GA, Poole K: Role of the acetyltransferase AAC(6')-Iz modifying enzyme in aminoglycoside resistance in Stenotrophomonas maltophilia. J Antimicrob Chemother 2003, 5 I:803-8I I.

36. Okazaki A, Avison MB: Aph(3')-Ilc, an aminoglycoside resistance determinant from Stenotrophomonas maltophilia. Antimicrob Agents Chemother 2007, 5 I:359-360.

37. Li XZ, Zhang L, Poole K: SmeC, an outer membrane multidrug efflux protein of Stenotrophomonas maltophilia. Antimicrob Agents Chemother 2002, 46:333-343.

38. Alonso A, Martinez JL: Multiple antibiotic resistance in Stenotrophomonas maltophilia. Antimicrob Agents Chemother 1997, 4 I: I| $40-$ I | 42

39. Alonso A, Martinez JL: Cloning and characterization of SmeDEF, a novel multidrug efflux pump from Stenotrophomonas maltophilia. Antimicrob Agents Chemother 2000, 44:3079-3086.

40. Zhang L, Li XZ, Poole K: Multiple antibiotic resistance in Stenotrophomonas maltophilia: involvement of a multidrug efflux system. Antimicrob Agents Chemother 2000, 44:287-293.

41. Sanchez P, Moreno E, Martinez JL: The biocide triclosan selects Stenotrophomonas maltophilia mutants that overproduce the SmeDEF multidrug efflux pump. Antimicrob Agents Chemother 2005, 49:781-782.
42. Sanchez P, Alonso A, Martinez JL: Regulatory regions of smeDEF in Stenotrophomonas maltophilia strains expressing different amounts of the multidrug efflux pump SmeDEF. Antimicrob Agents Chemother 2004, 48:2274-2276.

43. Sanchez P, Alonso A, Martinez JL: Cloning and characterization of SmeT, a repressor of the Stenotrophomonas maltophilia multidrug efflux pump SmeDEF. Antimicrob Agents Chemother 2002, 46:3386-3393.

44. Martinez JL: Antibiotics and antibiotic resistance genes in natural environments. Science 2008, 321:365-367.

45. Poirel L, Loo M Van De, Mammeri H, Nordmann P: Association of plasmid-mediated quinolone resistance with extended-spectrum beta-lactamase VEB-I. Antimicrob Agents Chemother 2005, 49:3091-3094.

46. Garnier F, Raked N, Gassama A, Denis F, Ploy MC: Genetic environment of quinolone resistance gene qnrB2 in a complex sull-type integron in the newly described Salmonella enterica serovar Keurmassar. Antimicrob Agents Chemother 2006, 50:3200-3202.

47. Venter JC, Remington K, Heidelberg JF, Halpern AL, Rusch D, Eisen JA, Wu D, Paulsen I, Nelson KE, Nelson W, et al.: Environmental genome shotgun sequencing of the Sargasso Sea. Science 2004, 304:66-74

48. Lockhart SR, Abramson MA, Beekmann SE, Gallagher G, Riedel S, Diekema DJ, Quinn JP, Doern GV: Antimicrobial resistance among Gram-negative bacilli causing infections in intensive care unit patients in the United States between 1993 and 2004. I Clin Microbiol 2007, 45:3352-3359.

49. Crossman LC, Gould VC, Dow JM, Vernikos GS, Okazaki A, Sebaihia M, Saunders D, Arrowsmith C, Carver T, Peters N, et al:: The complete genome, comparative and functional analysis of Stenotrophomonas maltophilia reveals an organism heavily shielded by drug resistance determinants. Genome Biol 2008 , 9:R74.

50. Rodriguez-Martinez JM, Velasco C, Pascual A, Garcia I, Martinez-Martinez L: Correlation of quinolone resistance levels and differences in basal and quinolone-induced expression from three qnrA-containing plasmids. Clin Microbiol Infect 2006, I 2:440-445.

51. Diaz-Guerra M, Esteban M, Martinez JL: Growth of Escherichia coli in acetate as a sole carbon source is inhibited by ankyrinlike repeats present in the 2',5'-linked oligoadenylatedependent human RNase L enzyme. FEMS Microbiol Lett 1997 , 149:107-113.

52. Bouma JE, Lenski RE: Evolution of a bacteria/plasmid association. Nature 1988, 335:351-352.

53. Martinez JL, Cercenado E, Rodriguez-Creixems M, Vincente-Perez MF, Delgado-Iribarren A, Baquero F: Resistance to beta-lactam/ clavulanate. Lancet 1987, 2: |473.

54. Martinez JL, Vicente MF, Delgado-Iribarren A, Perez-Diaz JC, Baquero F: Small plasmids are involved in amoxicillin-clavulanate resistance in Escherichia coli. Antimicrob Agents Chemother 1989, 33:595

55. Reguera JA, Baquero F, Perez-Diaz JC, Martinez JL: Factors determining resistance to beta-lactam combined with beta-lactamase inhibitors in Escherichia coli. J Antimicrob Chemother 1991, 27:569-575.

56. Thompson JD, Higgins DG, Gibson TJ: CLUSTAL W: improving the sensitivity of progressive multiple sequence alignment through sequence weighting, position-specific gap penalties and weight matrix choice. Nucleic Acids Res 1994, 22:4673-4680.

57. Altschul SF, Lipman DJ: Protein database searches for multiple alignments. Proc Natl Acad Sci USA 1990, 87:5509-55। 3.

58. Tatusov RL, Natale DA, Garkavtsev IV, Tatusova TA, Shankavaram UT, Rao BS, Kiryutin B, Galperin MY, Fedorova ND, Koonin EV: The COG database: new developments in phylogenetic classification of proteins from complete genomes. Nucleic Acids Res 2001, 29:22-28.

59. Tatusov RL, Koonin EV, Lipman DJ: A genomic perspective on protein families. Science 1997, 278:631-637.

60. Clamp M, Cuff J, Searle SM, Barton GJ: The Jalview Java alignment editor. Bioinformatics 2004, 20:426-427.

6I. Jacoby G, Cattoir V, Hooper D, Martinez-Martinez L, Nordmann P, Pascual A, Poirel L, Wang M: qnr Gene Nomenclature. Antimicrob Agents Chemother 2008.

62. Atlas RM: Handbook of Microbiological Media Boca Raton: CRC Press; 1993. 
63. Sambrook J, Russell DW: Molecular Cloning. A laboratory manual 3rd edition. Boca Raton: CRC Press; 2001.

64. Renart J, Behrens MM, Fernandez-Renart M, Martinez JL: Immnunoblotting techniques. In Immunoassay Edited by: Diamandis EP, Christopoulos TK. San Diego: Academic Press; 1996:537-554.

65. Morales G, Linares JF, Beloso A, Albar JP, Martinez JL, Rojo F: The Pseudomonas putida Crc global regulator controls the expression of genes from several chromosomal catabolic pathways for aromatic compounds. J Bacteriol 2004, 186: I337-1344.

66. Ma D, Cook DN, Alberti M, Pon NG, Nikaido H, Hearst JE: Genes acrA and acrB encode a stress-induced efflux system of Escherichia coli. Mol Microbiol 1995, 16:45-55.

67. Alonso A, Martinez JL: Expression of multidrug efflux pump SmeDEF by clinical isolates of Stenotrophomonas maltophilia. Antimicrob Agents Chemother 200I, 45:1879-188I.

68. Minkwitz A, Berg G: Comparison of antifungal activities and 16S ribosomal DNA sequences of clinical and environmental isolates of Stenotrophomonas maltophilia. J Clin Microbiol 200I, 39:139-145.

Publish with Bio Med Central and every scientist can read your work free of charge

"BioMed Central will be the most significant development for disseminating the results of biomedical research in our lifetime. "

Sir Paul Nurse, Cancer Research UK

Your research papers will be:

- available free of charge to the entire biomedical community

- peer reviewed and published immediately upon acceptance

- cited in PubMed and archived on PubMed Central

- yours - you keep the copyright

Submit your manuscript here:

http://www.biomedcentral.com/info/publishing_adv.asp
BioMedcentral 